\title{
Revistas subterráneas en la última dictadura militar argentina: la cultura en los márgenes
}

\author{
Evangelina Margiolakis ${ }^{1}$ \\ Un pájaro quedó encerrado \\ (primera clave) \\ y agitó sus alas con desesperación \\ se embistió una y otra vez \\ se embistió contra el vidrio hasta perder el miedo \\ (segunda clave) \\ y miró a su alrededor \\ en esa casa donde no habitan pájaros \\ y miró por el vidrio \\ su mundo desde esa casa \\ y cantó \\ Jorge Santiago Perednik, Claves para una poética, Revista Xul, n. 2, sept. 1981.
}

Resumen: Nos proponemos analizar el rol de las revistas culturales denominadas "subte" (subterráneas) o "underground" en la última dictadura militar argentina. Consideramos que durante este período, dichas publicaciones se vincularon con formaciones culturales que constituyeron la posibilidad de generar una trama colectiva y un espacio común de intervención. Ellas exploraron temas que se encontraban ausentes en otros espacios y construyeron una red de lazos sociales de cooperación y colaboración. Describiremos casos que resultan relevantes para reflexionar sobre el contexto en el que estas experiencias tuvieron lugar, analizando su proyecto de intervención intelectual, sus condiciones de producción y circulación, sus temáticas y tópicos de discusión. De esta manera, observaremos la relación que se estableció entre las distintas publicaciones y el lugar que tuvieron en la escena cultural.

Palabras clave: periodismo cultural, proyecto de intervención intelectual, dictadura militar.

\begin{abstract}
Our proposal is to analyze the role of cultural magazines denominated "underground" during the last argentine military dictatorship. We consider that during this period, these publications were linked to cultural formations that constituted the possibility of create a collective pattern and a common space of intervention. They explored issues that were absent on other spaces and built a link of social relationship of

\footnotetext{
${ }^{1}$ Becaria UBACyT del Doctorado en Ciencias Sociales de la Universidad de Buenos Aires. Docente de Teorías y Prácticas de la Comunicación II y de Didáctica de la Comunicación de la Facultad de Ciencias Sociales de la Universidad de Buenos Aires. Docente de Teoría de los Medios y la Cultura de la Facultad de Filosofía y Letras de la Universidad de Buenos Aires.
}

Revista Eletrônica da ANPHLAC, n.10, p. 64-82, jan./jun. 2011.

http://revista.anphlac.org.br/index.php/revista 
cooperation and help. We will describe some relevant cases in order to reflect on the context in which these experiences took place, analysing their project of intellectual intervention, the condition of their production and circulation and their main issues and topics of discussion. This way, we will observe the relationship established between the different publications and their place in the cultural scene.

Keywords: cultural journalism, project of intellectual intervention, military dictatorship.

\section{Introducción}

La propuesta es describir el rol de las revistas culturales denominadas "subte" (subterráneas) o "underground" en la última dictadura militar argentina (1976-1983). Durante este período, dichas publicaciones conformaron espacios colectivos de intervención político-cultural en un contexto de represión y terrorismo de Estado, explorando temas que se encontraban ausentes en otros espacios. Tales experiencias se caracterizaron por la constitución de redes de articulación y un modo de intervención común frente al contexto de opresión cultural. Ellas han sido rescatadas por tratarse de propuestas político-culturales y, en particular, por su enfrentamiento con las instancias del poder militar.

Se trataba de publicaciones vinculadas con formaciones ${ }^{2}$ o grupos culturales que se constituyeron como espacio de expresión, socialización y construcción de lazos colectivos. La elección de recursos formales o retóricos que realizaron les permitió hacer alusión a un contexto social y político signado por el terror. En algunos casos, las propuestas de estas producciones tuvieron relación con organismos de derechos humanos o partidos políticos, aunque el vínculo fuera indirecto y no orgánico debido al contexto de cruenta represión.

En cuanto a su modelo de intervención, varios autores rescatan la idea de "compromiso sartreano" que estuvo presente en estas prácticas, es decir, la concepción de que el intelectual no puede existir alejado de las luchas de otros sectores. Ellas

\footnotetext{
${ }^{2}$ Raymond Williams, define a las formaciones como: "los movimientos y tendencias efectivos, en la vida intelectual y artística, que tienen una influencia significativa y a veces decisiva sobre el desarrollo activo de una cultura y que presentan una relación variable y a veces solapada con las instituciones" en: WILLIAMS, Raymond. Marxismo y Literatura. Barcelona: Península, 1988.
}

Revista Eletrônica da ANPHLAC, n.10, p. 64-82, jan./jun. 2011.

http://revista.anphlac.org.br/index.php/revista 
constituyeron espacios alternativos para realizar reuniones y eventos como la difusión poetas y narradores, la discusión sobre corrientes estéticas como el surrealismo y la organización de ciclos de teatro, de cine o musicales. Por esta razón, se han abordado publicaciones vinculadas con la constitución de espacios colectivos de revistas, como la Asociación Argentina de Revistas Culturales — ARCA - y la Agrupación de Revistas Alternativas - ARA. Ellas son Poddema, Ulises, Nova Arte, Signo Ascendente, Ayesha, El Ornitorrinco, Sitio, Xul y Kosmos. A su vez, se tomaron publicaciones vinculadas - aunque no orgánica ni explícitamente debido al contexto imperante con partidos políticos como Contexto, Nudos, Cuadernos del camino y Propuesta para la juventud, entre otras. ${ }^{3}$

Por lo tanto, el artículo se propone describir la lógica particular que asumieron las revistas culturales "subterráneas" o "underground" durante la última dictadura argentina. ¿Es su oposición a lo comercial lo que las define? ¿Es por su lugar contrapuesto y diferenciado frente a las publicaciones que podríamos denominar como "de superficie”? ¿Ha sido su formato innovador lo que las caracterizó? Para responder a estos interrogantes, es necesario observar la relación de este tipo de experiencias con la denominada "cultura oficial", su lugar en el mercado de bienes simbólicos y su modo de intervención intelectual.

\section{Antecedentes de lo subterráneo}

Es importante tener en cuenta que la denominación "subterráneo" sólo es posible de pensar en términos históricos. En particular, en relación a un contexto de censura y represión. Es por ello que durante la denominada "transición democrática", estas experiencias se reacomodaron y sus propuestas experimentaron transformaciones.

\footnotetext{
${ }^{3}$ Se detallan las colecciones que fueron objeto de análisis:

- Poddema (1979- 1980). Director: Alberto Valdivia.

- Signo Ascendente (1981-1982). Redactores: Josefina Quesada, Juan Perelman y otros.

- Ulises (1978-1980). Directores: Horacio García, Horacio Tarcus, Gabriel Vega.

- Nova Arte. Revista bimestral independiente (1978-1980). Director: Enrique Záttara.

- Ayesha. Literatura (1978-1980). Director: Alejandro Margulis.

- Kosmos. Periodismo Alternativo (1979-1986). Director: Daniel Schapces.

- El Ornitorrinco. (1977-1986). Directores: Abelardo Castillo, Liliana Heker.

- Sitio (1981-1987). Redacción: Eduardo Grüner y otros.

- Xul. Signo viejo y nuevo. Revista de poesía (1980). Director: Jorge Santiago Perednik.

- Contexto (1977-1984). Editor: Juan Alberto Núñez, luego Ariel Bignami.

- NUDOS en la cultura argentina (1978-1992). Director: Manuel Amigo, luego Jorge Brega.

- Cuadernos del Camino (1978-1980). Directora: Mónica Giustina.

- Propuesta para la Juventud (1978-1979). Director: Roberto Catania.
}

Revista Eletrônica da ANPHLAC, n.10, p. 64-82, jan./jun. 2011. http://revista.anphlac.org.br/index.php/revista 
El término "subterráneo" o "underground" tiene sus antecedentes en aquellas publicaciones que presentaron una opción diferencial frente al mercado o al predominio de una "estética oficial". Se multiplicaron en un contexto caracterizado por la imposición de mecanismos de censura y represión. En Estados Unidos, la aparición de este tipo de publicaciones coincide con la emergencia de los movimientos beat y hippie y con fenómenos anti-industria cultural, que dieron origen a la aparición de "Underground Press Syndicate" (Sindicato de Prensa Subterránea). Trabajaron en las vertientes de la experimentación literaria, la crítica al sistema, la cultura de la droga, la liberación sexual, las campañas por los derechos civiles, el rock y la crítica a la guerra de Vietnam, entre otros tópicos. ${ }^{4}$

En Argentina, la prensa "subte" tiene sus orígenes hacia mediados de los '60, durante el golpe de Onganía. En la última dictadura, nacieron y se multiplicaron gran cantidad de publicaciones "subte", las cuales rápidamente adoptaron esta autodenominación. Abordaron temas como la insurrección popular en países latinoamericanos, los Derechos Humanos, el lugar del escritor, el vínculo entre estética y política, entre otros. ${ }^{5}$ Cabe aclarar que no sólo se habló de "subterráneo" a partir del golpe de 1976, sino también durante el gobierno de Isabel Perón y el accionar represivo de la Triple A. Por ello, existe cierto consenso entre los protagonistas de las experiencias, en que la denominación incluye una década que va aproximadamente entre 1974 y 1984, momento en que la "transición” obliga a estas prácticas a reubicarse paulatinamente.

Por su parte, la denominación de "alternativa" tiene sus orígenes, en el caso de América Latina, a mediados de la década de 1970 y durante la década siguiente. Refiere a una serie de prácticas y reflexiones que surgen luego del fracaso de la implementación de Políticas Nacionales de Comunicación. Más allá de las diferencias respecto de su definición - en especial, la discusión acerca de si la comunicación alternativa debe o no estar inscripta en una praxis transformadora de la estructura social —, la alternatividad implica una opción diferencial frente a la estructura de propiedad, formas de organización y contenidos que han adoptado los medios masivos. ${ }^{6}$ Se apropia, entre

\footnotetext{
${ }^{4}$ Para mayor información, léase: RIVERA, Jorge B. El periodismo cultural. Buenos Aires: Paidós, 1995. p. 100.

${ }^{5}$ Para mayor información, léase: MERO, Roberto. Revistas culturales. El aire contra la mordaza. Revista El Porteño, año 1, n. 3, marzo 1982.

6 Para mayor información, léase: SIMPSON GRINBERG, Máximo (Compilador). Comunicación alternativa y cambio social. México: Premia Editorial, 1986.
}

Revista Eletrônica da ANPHLAC, n.10, p. 64-82, jan./jun. 2011.

http://revista.anphlac.org.br/index.php/revista 
otros, de diversos paradigmas teóricos vinculados a procesos latinoamericanos como la Teología de la Liberación, la Pedagogía Freiriana y la Teoría de la Dependencia, así como retoma elementos vinculados con el acceso, la participación y la horizontalidad en la producción de mensajes.

Durante la dictadura, la autodenominación de "subterráneas" o "alternativas" se fue generalizando de forma espontánea aunque no azarosa, sin producirse mayores discusiones al respecto. Ambos calificativos fueron utilizados indistintamente. De esta manera, conformaron una zona diferenciada respecto de otras publicaciones. Una muestra de esto lo constituye el hecho de que varios kioscos de revistas incluyeron un panel completo dedicado a las revistas "alternativas". En un caso u otro, la caracterización refería a aquello que se encontraba en el "límite" o al "margen" de lo "establecido", que intentaba ir "más allá", que proponía otra jerarquización de temas y claves de lectura, diferentes de las que provenían de otro tipo de publicaciones, que pasaremos a denominar "de superficie", vinculadas con la denominada "cultura oficial".

\section{Algunas características específicas de las publicaciones}

El trabajo se propone reflexionar sobre los elementos comunes de las publicaciones, en especial, describir la postura común asumida y el vínculo de “disidencia" u "oposición" respecto del poder militar. Sin embargo, el propósito de este apartado consiste en avanzar en la caracterización de diferentes revistas en cuanto a sus corrientes estéticas, modos de intervención y tópicos temáticos. Tomaremos para ello una serie de publicaciones representativas y paradigmáticas que permiten reponer el amplio abanico de experiencias.

En 1977 surgía El Ornitorrinco, dirigida por Abelardo Castillo, quien ya contaba con cierta trayectoria como escritor. La revista retomaba el pensamiento de Sartre y su rescate del "escritor comprometido". Como otras revistas, El Ornitorrinco surge de un taller literario, espacio de encuentro que tuvo gran relevancia en la dictadura. En palabras de Castillo, el propósito era enfrentar desde la cultura a la dictadura militar, intentando desafiar los límites impuestos por la censura: "Siempre sostuve que las dictaduras y censuras tienen un punto débil en la cultura y es el punto oblicuo que tiene la cultura para señalar algunos hechos". 7 Además del recurso del humor y de cuentos

\footnotetext{
${ }^{7}$ Entrevista a Abelardo Castillo. Abril de 2011.
} 
que hacían alusión a la "prohibición”, la revista intervino muy críticamente durante el conflicto con Chile por el Canal de Beagle. Con el mismo énfasis, rescató la tarea de las Madres de Plaza de Mayo respecto de su lucha por los Derechos Humanos.

En 1978 surgía Ulises, la que luego, a partir de su n. 3, se uniría a Nova Arte. La revista presentaba la impronta de la militancia vinculada a la tradición trotskista, ya que muchos de sus integrantes habían participado en Política Obrera. En sus páginas, se intentaba retomar el pensamiento de Lukàcs y se planteaba la necesidad de encontrar un espacio de articulación ente literatura y formas estéticas por un lado, y el "ser social", por el otro.

En 1979, surgía la revista Antimitomanía, preocupada por la divulgación de la filosofía beat y los movimientos contraculturales vinculados con la "nueva izquierda" en Estados Unidos. Por ello se hacía referencia a la cultura hippie y al pensamiento de Thomas Merton, Jack Kerouac y Allen Ginsberg. El espacio otorgado a la poesía era primordial. Esto llevó a conformar un colectivo denominada GATA — Grupo Alternativo de trabajo Antimitomanía - a partir del cual se organizaron encuentros de música y poesía.

A su vez, es importante mencionar dos publicaciones vinculadas con la difusión del surrealismo. Por un lado, Poddema nacía en 1979 y por el otro, Signo Ascendente lo hacía en 1981. El rescate del surrealismo permitía recuperar la esfera del inconsciente, lo que a su vez implicaba enfatizar en el "deseo", aun en un contexto de censura y silenciamiento. En el caso de Signo Ascendente, la revista intervino públicamente en la guerra de Malvinas, elaborando notas críticas sobre el conflicto bélico.

Kosmos, revista de carácter periodístico, surgía en 1979, como iniciativa de un grupo de estudiantes de periodismo. Se autodefinieron como "periodismo alternativo", lo que significaba realizar balances sobre sindicalismo, Derechos Humanos y en particular, fue pionera en la difusión del género de la crítica cultural de medios. Sus notas se centraban en un enfoque sociológico de las temáticas.

En 1980, surgía la revista $X u l$, asignando gran importancia a la poesía. Para Santiago Perednik, su editor, la poesía era un territorio de creación, libertad y un espacio de confrontación de ideas. Además de poemas, la revista incluía reflexiones sobre corrientes estéticas como el caso de la poesía concreta en Argentina.

Hacia 1981 surgía Sitio, la que se reconocía heredera de su antecesora, Literal. La publicación privilegiaba el análisis del discurso, el estructuralismo, la antropología y 
el psicoanálisis. La reivindicación del lenguaje implicaba tomar como punto de partida el arte de "escribir entre líneas", comprendiendo la importancia asignada a las "palabras".

Nos detendremos en algunas publicaciones vinculadas, aunque no de manera orgánica por el contexto de censura y represión, a tradiciones de partidos políticos de izquierda. En primer lugar, hacia 1977 surgía Posta, que luego de sus tres primeros números pasaría a denominarse $N u d o s .{ }^{8}$ Varios de sus miembros estaban vinculados a la tradición maoísta del Partido Comunista Revolucionario Argentino. Esto se evidenciaba en su rescate de la cultura nacional, popular y antiimperialista. La importancia asignada a la poesía de la mano de Jorge Brega y a las artes plásticas a través de las expresiones pictóricas de Manuel Amigo, implicó la posibilidad de "mostrar" la censura y desapariciones: "La dictadura era para nosotros un momento atroz pero al mismo tiempo, era una cuestión de ubicarnos en eso, luchar para vivir y hacer las cosas que teníamos que hacer". 9

Por su parte, también en 1977 surgía Contexto, vinculada con el Partido Comunista Argentino. La publicación fue una iniciativa política y cultural en un momento en el que la revista cultural oficial del Partido, Cuadernos de Cultura, se encontraba prohibida. Contexto rescataba tradiciones temáticas vinculadas al Partido Comunista, como el teatro de Brecht, el realismo socialista, la vida cotidiana en la Unión Soviética y la herencia estética de Carlos Marx. De manera local, se reflexionaba sobre la experiencia de Teatro Abierto, el tango y la figura de Héctor P. Agosti, militante muy reconocido en el Partido Comunista en Argentina y que supo incorporar tempranamente en nuestro país el pensamiento de Antonio Gramsci. Para quien fue su director, Ariel Bignami, "El PC partía de un análisis que, con los años, se reveló equivocado". ${ }^{10}$ Tal caracterización consideraba la existencia de una supuesta "diversidad" dentro del aparato militar que permitía establecer diferencias respecto de otras dictaduras en América Latina. Fue en el $16^{\circ}$ Congreso del Partido, luego de instaurada la democracia, cuando tal análisis fue revisado críticamente.

Por su parte, encontramos dos publicaciones vinculadas al trotskismo, en particular, al PST (Partido Socialista de los Trabajadores). Por un lado, Propuesta para

\footnotetext{
${ }^{8}$ El cambio de nombre de la revista se debió a que el nombre Posta ya aparecía registrado por otros autores.

${ }^{9}$ Jorge Brega. Charla realizada en la Muestra Homenaje a Manuel Amigo. San Fernando, Abril de 2011.

${ }^{10}$ Entrevista a Ariel Bignami. Abril de 2011.
}

Revista Eletrônica da ANPHLAC, n.10, p. 64-82, jan./jun. 2011.

http://revista.anphlac.org.br/index.php/revista 
la Juventud surgía hacia 1977 en Quilmes. Otorgaba un lugar importante a la poesía, la música, el arte, los jóvenes y sus "sueños”. Otra publicación vinculada con el PST fue Cuadernos del Camino, surgida en 1978. La revista discutía con el realismo socialista - rescatado por la tradición del Partido Comunista - y destacaba el aporte del surrealismo y temáticas vinculadas con el cuerpo, el género y las sexualidades. Se dedicó a problematizar sobre la vanguardia y concibió el lugar de la literatura como espacio de "militancia".

Si bien las experiencias son específicas e implican diversos modelos de política cultural, se analizarán seguidamente los elementos que presentaron en común en un contexto de censura y represión.

\section{Lo "subterráneo" y la dictadura:}

\section{Algunos denominadores comunes que caracterizaron a este tipo de publicaciones}

\section{La posición en el mercado simbólico}

Si observamos la lógica del mercado de los bienes simbólicos, ubicaríamos a las publicaciones "subte" en el polo opuesto a las revistas comerciales, polo que Bourdieu denominaría "la lógica antieconómica del arte puro", cuyo valor no estaría dado por el beneficio económico. Es que luego de un proceso de especialización, en cada polo se ubicarían, por un lado, una producción cultural destinada especialmente al mercado, y por el otro, una serie de obras que estarían mayoritariamente destinadas a la apropiación simbólica. Mientras que en las primeras prima el capital económico, las segundas se orientan hacia la acumulación de capital cultural. ${ }^{11}$

En referencia a la lógica "antieconómica" de las revistas culturales "underground", si bien su modo de financiamiento resultaba ser autogestivo, podía recurrirse a alguna publicidad, aunque ella no fuera su principal fuente de sustentación económica. En contraposición a las revistas comerciales, se intentaba caracterizar estas experiencias: "Contra esto, las publicaciones subterráneas grandes y chicas, no

\footnotetext{
${ }^{11}$ BOURDIEU, Pierre. El mercado de los bienes simbólicos. In: Las reglas del arte. Génesis y estructura del campo literario. Barcelona: Anagrama, 1995. p. 213-261.
} 
dependen de la publicidad, y por lo tanto, poseen una línea independiente que permite abordar cualquier tema sin mordazas". ${ }^{12}$

Existió de este modo, la autopercepción de que su lógica no comercial les otorgaba mayor libertad - al menos, respecto del mercado - para "decir". Así, podemos plantear que asumieron el rol de tratar aquellos problemas y discusiones que no podían ser visibilizados en otros espacios de intervención colectiva. Un análisis de los temas jerarquizados permite observar notas dedicadas a los Derechos Humanos varias revistas incluían reflexiones y reportajes a Adolfo Pérez Esquivel —, la crítica a la censura, la oposición a la Guerra de Malvinas, el rescate de expresiones de la cultura popular, el rock, la experimentación en el terreno de la literatura y la pintura.

Es importante destacar que estas publicaciones no circulaban necesariamente de modo "clandestino", aunque en muchos casos las notas se firmaban bajo seudónimos y no aparecía ninguna dirección o teléfono visible, sólo una casilla postal. Su circulación se centraba en el intercambio "mano a mano", o bien, a partir de la venta de escasos números en algunos kioscos de revistas que incluían en sus paneles publicaciones de este tipo.

Si bien la posición en el mercado de los bienes simbólicos es importante para observar los elementos que caracterizan este tipo de publicaciones, el análisis debe realizarse teniendo en cuenta no sólo el financiamiento, la finalidad o su circulación sino incluyendo además, aspectos como sus temáticas, tradiciones que se rescatan y en especial, su relación con la cultura "oficial", su modo de intervención intelectual y su política cultural.

\section{La intervención cultural como modo de intervención política}

La discusión en términos "culturales" y el espacio estratégico otorgado a lo simbólico en este tipo de publicaciones, fue correlato de que lo político se encontraba vedado. Muchas de las discusiones en clave "literaria" o de "crítica cultural" implicaron dar cuenta del contexto histórico, a pesar de que el modo de describirlo fuera a partir de figuras retóricas como la "metáfora", la "elispsis" o la "alegoría".

Como caso significativo, la revista Nudos, que formó parte de la experiencia de Asociación de Revistas Culturales (ARCA), incluyó en sus páginas las expresiones

\footnotetext{
${ }^{12}$ MERO, Roberto. Revistas culturales. El aire contra la mordaza. Revista El Porteño, año 1, n. 3, marzo 1982.
}

Revista Eletrônica da ANPHLAC, n.10, p. 64-82, jan./jun. 2011.

http://revista.anphlac.org.br/index.php/revista 
plásticas de Manuel Amigo y la poesía de Jorge Brega, ambos directores de la revista Amigo en los primeros números y Brega a partir del n. 3 y hasta su finalización - La necesidad de denunciar la desaparición forzada de personas durante la dictadura estuvo presente en la obra de ambos artistas. Entre 1976 y 1983, Brega publicó en la revista una serie de poemas con los que luego, en 1984, armaría una compilación titulada Poemas de Ausencia. ${ }^{13}$ Durante 1978, Manuel Amigo comenzó a trabajar en su serie Objetos. Gran parte de ese material se mostró en la revista. Amigo intervino plásticamente elementos domésticos en desuso: zapatos, juguetes, prendas de vestir, utensilios de cocina, herramientas, colillas, trozos de pan. El procedimiento de colorearlos con tonos grises y recubrirlos con una mezcla de arena, cola y yeso, confirió al conjunto un aspecto fósil, remitiendo a fotografías de restos hallados en campos de concentración. Amigo supo resumir su trabajo en el n. 7 de la revista Nudos en julio de 1980:

\begin{abstract}
Tomados como monumentos, mis trabajos son un homenaje a seres anónimos. En cierta forma también son altares, pero no para adorar a los objetos reunidos en ellos, sino para no olvidar a las personas que evocan. Son altares que mucha gente ha erigido en su interior. Yo trato de sacarlos afuera y mostrarlos (...) Los bultos, los paquetes abandonados, han obsesionado a los artistas por lo siniestro de su imagen. El que yo utilice zapatos y oras prendas que alguien ha vestido, es porque tienen un poder de perpetuar presencias que yo utilizo con un sentido preciso.(...) Si yo utilicé esos zapatos que hallé por ahí, fue porque me transmitieron un drama. Ese drama reside en la ausencia de su dueño. ${ }^{14}$
\end{abstract}

Los trabajos plásticos de Manuel Amigo nos permiten observar cómo, a partir de figuras retóricas como la elipsis y la metáfora ${ }^{15}$, se intentaba representar las ausencias. El lugar relevante otorgado a las expresiones pictóricas y poéticas era una forma de intervenir colectiva y políticamente. Eso es lo que explica el rescate tan significativo de la figura del "poeta" y, por extensión, a todo aquel que trabajara experimentando en la búsqueda de expresiones culturales de diversas formas: el escritor, el pintor, el escultor, el cineasta, el músico.

\footnotetext{
${ }^{13}$ BREGA, Jorge. Poemas de Ausencia. Objetos y dibujos: Manuel Amigo. Buenos Aires: Ágora, 1984.

${ }^{14}$ Manuel Amigo. Entrevista. Revista Nudos, Buenos Aires, n. 7, p. 13-14, jul. 1980.

15 Definiremos metáfora como una figura retórica en la que tienen lugar operaciones de adición y supresión. En ella se plantean entre dos términos en juego en la que uno es sustituido por otro. Se reemplazan así objetos o personajes por otros que son portadores de un sentido figurado, donde no se hace mención al objeto sino que se lo sustituye por alguno de sus valores. Por su parte, la elipsis es una figura retórica de supresión que elimina ciertos elementos de un texto como personajes, objetos y aun el mismo objeto seleccionado, el cual, por lo tanto, es percibido como incompleto aunque remitiendo a una totalidad ausente.
}

Revista Eletrônica da ANPHLAC, n.10, p. 64-82, jan./jun. 2011. http://revista.anphlac.org.br/index.php/revista 
También en mayo de 1982, la revista Signo Ascendente, dedicada a la apropiación del surrealismo en Argentina, publicaba en su editorial reflexiones acerca de la figura del lugar del poeta:

\begin{abstract}
En este país, donde algunos ya se han mostrado tan propensos a censurar lo que no pueden asimilar, a tocar con sus manos nacionales cuanto está a su alcance, a desvirtuar lo que en su esencia proviene de un estado más puro de libertad, y en cuya historia ya hay signos inequívocos de barbarie tal como el imborrable hecho de miles y miles de desaparecidos, en este país, afirmamos, son a nuestro juicio no menos que una crítica y una denuncia implacables las que deben caracterizar la actitud que salvaguarde en su integridad moral al verdadero poeta. ${ }^{16}$
\end{abstract}

Frente a la censura imperante y el contexto represivo, la figura del poeta constituía un espacio donde "salvaguardarse", un refugio posible, una forma posible de nombrar al "militante". La preocupación por lo estético daba cuenta de la imposibilidad por mencionar aquello que pertenecía a otro campo: lo que se había transformado era el modo de enunciarse como sujetos políticos.

La primera editorial de El Ornitorrinco n. 1, concebida como un "manifiesto", también proponía "poner lo estético, en literatura, por encima de cualquier otra valoración". ${ }^{17}$ A lo largo de todas sus editoriales se rescataba la figura del "escritor" y también del "creador". Esto queda evidenciado en su editorial n. 5:

\begin{abstract}
Escribir libros, o más modestamente sacar revistas, contribuir de algún modo a que nuestro pueblo siga cantando y hablando por boca de sus poetas y de sus escritores, y a que la palabra "cultura" no se petrifique en una mera descripción etnológica, esa es la responsabilidad de todos los intelectuales argentinos. (...) Los libros tienen un Destino, decían los antiguos. Y lo tienen. No sólo duran más que quienes los amamos sino que quienes los detestan o les temen. Pensar en esto último, puede devolverle a cualquiera esa secreta alegría que, aún en plena angustia, en plena incertidumbre, hace falta para seguir escribiendo. ${ }^{18}$
\end{abstract}

Nuevamente aparece el rescate del escritor en momentos de incertidumbre, la necesidad del pueblo de seguir hablando por medio del "poeta", de seguir escribiendo para que la palabra perdure, para que la voz no calle y se perpetúe por encima de la angustia.

\footnotetext{
${ }^{16}$ Presentación. Revista Signo Ascendente, n. 2-3, p. 1-2, mayo 1982.

${ }^{17}$ CASTILLO, Abelardo. Editorial: Muerte y resurrección de las revistas literarias o seis aproximaciones para armar un ornitorrinco. Revista El Ornitorrinco, Buenos Aires, n. 1, p. 1-2, oct.-dic. 1977.

${ }^{18}$ Editorial: Los derechos de la inteligencia o el huevo dorado. Revista El Ornitorrinco, Buenos Aires, n. 5, p. 1, enero-feb. 1979.
}

Revista Eletrônica da ANPHLAC, n.10, p. 64-82, jan./jun. 2011. http://revista.anphlac.org.br/index.php/revista 
La militancia política se encontraba excluida de la esfera pública. Sin embargo, proponer la creación de una revista cultural y participar en ella, era concebido como una forma de "militancia”. En 1979, Enrique Záttara en Cuadernos del Camino rescataba el rol de ciertas revistas culturales - haciendo referencia a las revistas "subte" como $E l$ Ornitorrinco, Nudos, Ayesha, Nova Arte, Contexto y Ulises - y planteaba que la forma de expresarse en una revista implicaba una visión de mundo y por ende, una forma de militancia.

\begin{abstract}
Si poemas o cuentos son el modo de expresar una visión donde el concepto ocupa lugar secundario (aunque esto es dudoso, y eso sería objeto de otra discusión), la revista es una creación cuyo objetivo es transmitir una concepción coherente de la realidad, o por lo menos (en el caso de que trato) de una parcela de esa realidad, la literatura y el arte. Si la obra personal representa mi expresión artística, lo que haga en la revista será una militancia, la militancia por una concepción en la que se sustenta aun la propia obra. (...) La idea de una "militancia" que trasciende el marco de la realización puramente expresiva es sin duda una cuestión que el artista se plantea, en tanto se le hace evidente que - aunque inseparables - esa obra personal de que hablamos (la realización estética) se le impone como primordial. ${ }^{19}$
\end{abstract}

La palabra "militancia" aparecía de modo más explícito en una publicación como Cuadernos del Camino. De esta manera, el espacio construido por las revistas excedía lo expresivo.

Hemos podido observar el vínculo particular entre "estética” y "política”. Si bien en el campo político, la "militancia" había dejado de existir, en el campo de las revistas culturales, la posibilidad de escribir era concebida no sólo como un modo de supervivencia sino como una nueva "práctica militante". De esta manera, el modelo de intervención intelectual tomaba lo estético como punto de partida para trascender lo meramente expresivo y transmitir una visión de mundo que permitiera intervenir políticamente.

\title{
La ruptura y relación con la tradición anterior
}

Todo proyecto editorial implica el reconocimiento y a su vez, la ruptura con tradiciones anteriores. De esta manera, podemos plantear que Sitio se reconocía heredera de Literal, El Ornitorrinco retomaba la tradición de El Escarabajo de Oro, así

\footnotetext{
${ }^{19}$ ZÁTTARA, Enrique. Revistas Literarias: vehículo de reflexión en la cultura. Cuadernos del Camino, n. 3, p. 31-32, sept. 1979.
}

Revista Eletrônica da ANPHLAC, n.10, p. 64-82, jan./jun. 2011.

http://revista.anphlac.org.br/index.php/revista 
como Punto de Vista ${ }^{20}$ se reconocía heredera de Los Libros ${ }^{21}$, en particular, en el terreno de la crítica cultural. Es que al analizar estas publicaciones debemos tener en cuenta el "legado" de aquellas publicaciones de las décadas de los '60 y ' 70 , el cual se retoma en algunos casos y en otros, se discute.

Un elemento a destacar en relación con las discusiones estéticas, es la apropiación particular del surrealismo que realizaron revistas como Ulises, Poddema y Signo Ascendente, entre otras. Dicha apropiación implicaba el rescate del legado de un movimiento histórico de vanguardia que, aunque surgido en Europa en décadas anteriores, asumía particulares características al ser retomado en el contexto de la dictadura argentina.

Signo Ascendente encontraba en el surrealismo la posibilidad de profundizar, por un lado, en lo "desconocido" - en referencia al "inconsciente" - y por el otro, en una actitud opositora a la situación social imperante: "el surrealismo ha de continuar sumergido en lo más profundo de las aguas cálidas, en aguas del deseo, allí donde es posible hallar la transparencia del cristal en la vida misma". ${ }^{22}$ La recuperación del inconsciente era concebida como la posibilidad de liberar el deseo y lo oculto.

En el caso de Ulises, que incluía en su staff a lectores de la estética marxista, se observaba al movimiento desde cierta tensión entre la admiración y empatía que generaba el surrealismo y cierta actitud crítica en relación con la estética romántica del movimiento. Para Horacio Tarcus, director de la publicación, esto era la síntesis de discusiones que tenían con el grupo surrealista de Buenos Aires que editaba la revista Poddema ${ }^{23}$ : "Intentábamos hacer una síntesis rara entre Lukàcs en clave de izquierda con cierto trotskismo y con una apuesta por un realismo superador de las viejas antinomias y en el número 0 , tomamos a Cortázar como paradigma".

En la Editorial n. 0 de Ulises, se planteaba la necesidad de contribuir a nuevas formas expresivas, superando la polarización entre esteticismo — representada por la tradición inaugurada por el Grupo Florida - y realismo —en referencia al Grupo Boedo, preocupado por el contenido. Para la revista, era necesario buscar una nueva

\footnotetext{
${ }^{20}$ Punto de Vista. Revista de Cultura. Directores: Jorge Sevilla. A partir del n. 12, Beatriz Sarlo. N. 1: marzo de 1978. N. 90: abril de 2008.

${ }^{21}$ Revista Los Libros. N. 1: junio de 1969. N. 44: enero/febrero de 1976. Directores: Héctor Schmucler (hasta el n. 29), Beatriz Sarlo, Carlos Altamirano y Ricardo Piglia (a partir del n. 29 y hasta el n. 40), Beatriz Sarlo y Carlos Altamirano (n. 41).

${ }^{22}$ Presentación. Revista Signo Ascendente, n. 2-3, p. 1-2, mayo 1982.

${ }^{23}$ Revista Poddema. Publicación Periódica par la actividad poética independiente. Director: Alberto Valdivia. N. 1: 1979. N. 2: 1980.
}

Revista Eletrônica da ANPHLAC, n.10, p. 64-82, jan./jun. 2011.

http://revista.anphlac.org.br/index.php/revista 
síntesis, consolidando nuevas formas expresivas. En la editorial de aquel n. 0, se expresaba que:

Los ideales estéticos de cada movimiento artístico cristalizan en normas estéticas que sus autores pretenden universales y absolutas. (...) Pero una vez ampliado el horizonte de la realidad, los moldes estéticos heredados resultan inadecuados para expresar eficazmente esa nueva visión del mundo. (...)Ulises proclama la caducidad de las normas estéticas heredadas, así como la cosmovisión recibida. ${ }^{24}$

La crítica a la concepción de un arte "autónomo" quedaba en evidencia así como la necesidad de pensar un arte en vinculación con la vida, superando aquella tensión entre "esteticismo" y "contenidismo". De esta manera, proponía un nuevo arte para un nuevo hombre. Esta misma inquietud estaba presente en publicaciones como Nudos, la cual proponía superar la polémica entre "realismo" y "esteticismo".

\section{La conformación de grupos culturales}

Las publicaciones "subte" fueron el reflejo de una serie de inquietudes que diversos grupos tuvieron y necesitaron plasmarlo en este tipo de producciones. La experiencia grupal no sólo implicaba el proyecto editorial sino la conformación de grupos de estudio y discusión vinculados a la literatura, la música, la poesía, el debate teórico y político. Esos "grupos culturales" se vincularon entonces con formaciones que constituyeron la posibilidad de generar una trama colectiva y un espacio común de intervención aun en un contexto de fuerte represión y terrorismo de Estado. Para muchos, no sólo respondió a un "instinto de supervivencia", sino a "un impulso de vida". Para el director de Antimitomanía Daniel Serra, es posible identificar diferencias entre el momento de la dictadura y el momento posterior, en referencia al gobierno de Alfonsín, "lo anterior fue un movimiento muy instintivo a darnos vida entre nosotros y a poetizar hasta que acabe". 25

A modo de ejemplo, la experiencia ligada a publicaciones como Antimitomanía se autocaracterizó como "movimientista", es decir, constituida por redes de publicaciones, encuentros de poesía y música como el Centro Cultural Estudio en San Miguel y la conformación de GATA, Grupo Alternativo de trabajo Antimitomanía, a

\footnotetext{
${ }^{24}$ Editorial: Justificación. Revista Ulises, n. 0, p. 2-3, abril 1978.

${ }^{25}$ Entrevista realizada a Daniel Serra, director de la Revista Antimitomanía. Buenos Aires, julio de 2010.
}

Revista Eletrônica da ANPHLAC, n.10, p. 64-82, jan./jun. 2011.

http://revista.anphlac.org.br/index.php/revista 
partir del cual se reunían a estudiar, leer, discutir, articular música, rock y diversos movimientos ecológicos, entre otros.

Más allá de su persistencia en el tiempo, sus transformaciones, sus polémicas, la existencia misma de las revistas culturales en tiempos de dictadura indicaba, incluso en términos de sus protagonistas, un estado permanente de ebullición en la actividad intelectual, marginada de los circuitos habituales y revelaba la voluntad de crear, producir, intervenir en momentos donde — aun con límites, censura y autocensura quedaba sólo la palabra.

Es importante, a su vez, enfatizar no sólo en la conformación de grupos al interior de una revista sino también en la relación entre diferentes publicaciones culturales, las cuales, más allá de sus líneas editoriales y corrientes estéticas particulares, encontraron un espacio conjunto de articulación a partir del que exploraron temas ausentes en otros ámbitos y construyeron una red de lazos sociales de cooperación y colaboración. De esta manera, hacia 1979 surgía la Asociación de Revistas Culturales (ARCA) conformada por Poddema, Ulises, Galaad, Nova Arte, Signo Ascendente, Ayesha, Cuadernos del Camino, Nudos, Oeste y El Ornitorrinco, entre otras. Tras algunos encuentros, las revistas que formaron parte del colectivo ARCA, realizaban en 1979 una conferencia de prensa donde expresaban su oposición a la censura imperante. ${ }^{26}$ Posteriormente, surgía la Agrupación de Revistas Alternativas (ARA) conformada por Kosmos, Todos Juntos y Quijote, entre las publicaciones más relevantes. Ellas constituyeron un modo particular de intervención colectiva, discusión y puesta en común de intereses.

Podemos observar así, una serie de diálogos, citas y reconocimientos al interior de las publicaciones que formaban parte de estas experiencias colectivas de articulación. En enero de 1979, El Ornitorrinco publicaba una nota en la que celebraba el surgimiento de Nova Arte:

Estas revistas remueven el clima cultural de un país mostrando que quienes especulaban con un supuesto aquietamiento del impulso creador entre nosotros se equivocan. Lo otro evidente es que los jóvenes que en general son quienes, con grandes sacrificios las hacen, no encuentran acceso a otros canales de expresión. ${ }^{27}$

\footnotetext{
${ }^{26}$ GUIARD, Silvia. Buenos Aires: el surrealismo en la lucha contra la dictadura. In: LÖWY, Michael. La estrella de la mañana: surrealismo y marxismo. Buenos Aires: El cielo por asalto, 2006.

${ }^{27}$ Revista El Ornitorrinco, n. 5, p. 26, enero-feb. 1979. Directores: Abelardo Castillo y Liliana Heker.
}

Revista Eletrônica da ANPHLAC, n.10, p. 64-82, jan./jun. 2011.

http://revista.anphlac.org.br/index.php/revista 
La cita cobraba una significatividad distinta: implicaba dialogar, romper el aislamiento, instar al diálogo, generar redes de sociabilidad, reconocerse en otras experiencias. Y lo que mostraba era la ausencia de otros canales de expresión para esas jóvenes generaciones.

Respecto de las actividades y discusiones al interior de espacios como el constituido por ARCA, ellas incluían encuentros de poesía en centros culturales como "La Casona de Iván Grondona" o la "Casa del Sol”, así como momentos de discusión de cuestiones políticas y gremiales. En palabras de Jorge Brega, director de Nudos: "Lo fundamental era tratar de unirse y defenderse porque era muy clandestino el trabajo de la revista cultural (...) Había un miedo bárbaro. Entonces, al salir a la calle a distribuir esas revistas, nunca sabíamos qué podía pasar". ${ }^{28}$ Como principal punto, aparecía la necesidad de reivindicar la libertad de expresión como consigna en contra de la censura dominante, a partir de manifestaciones o declaraciones en contra de la dictadura. Por otro lado, se proponía un programa cooperativo, intentando aunar esfuerzos para obtener, por ejemplo, menores costos de impresión o socializando cuestiones vinculadas con la edición y diagramación.

Es importante destacar que en ese momento, la prioridad fue la necesidad de crear un frente común basado en la articulación de experiencias, hecho que queda demostrado en la conformación de colectivos de publicaciones que, aun siendo disímiles y heterogéneas, no se proponían un debate explícito. Horacio Tarcus planteaba en referencia a aquel momento: "Todo el mundo sabía quién es quién pero nadie sacaba los pies del plato porque eran los tiempos de la dictadura. Entonces, las actividades se hacían en común y había mucha solidaridad."29

No podemos negar las diferencias entre publicaciones en cuanto a corrientes estéticas a las que adscribieron y su modelo de intervención intelectual y política. Sin embargo, esas diferencias no se explicitaron públicamente hasta los primeros años del gobierno de Alfonsín. Es allí cuando se comenzaron a visualizar ciertas polémicas y se produjo un reacomodamiento de estas publicaciones. El nuevo contexto implicó el pasaje de varios temas — que antes sólo habían tenido lugar en las revistas "subte" — a la esfera pública y a su vez, obligó a las revistas a definir su perfil y política cultural. Algunas se volcaron al mercado para lograr una difusión masiva o bien, dejaron de

\footnotetext{
${ }^{28}$ Entrevista realizada a Jorge Brega, director de la Revista Nudos. Buenos Aires, julio de 2010.

${ }^{29}$ Entrevista realizada a Horacio Tarcus, director de la Revista Ulises. Buenos Aires, diciembre de 2002.
}

Revista Eletrônica da ANPHLAC, n.10, p. 64-82, jan./jun. 2011.

http://revista.anphlac.org.br/index.php/revista 
existir porque los grupos que las crearon sintieron la necesidad de intervenir en otros espacios.

\section{A modo de cierre}

La historia de las revistas culturales "subterráneas" durante la última dictadura militar argentina nos permite observar modelos de intervención intelectual y de esta manera, indagar en las relaciones entre política y cultura. Deseo puntualizar, a modo de conclusiones parciales, algunos elementos. En primer lugar, es necesario destacar que varias de las experiencias descriptas se encuentran fuertemente vinculadas con tradiciones políticas y estéticas de publicaciones paradigmáticas de las décadas del '60 y '70, en lo que refiere a la crítica cultural y a ciertos debates.

Al inicio de este artículo nos preguntábamos qué elementos comunes estaban presentes en este tipo de publicaciones. Podemos sostener que no ha sido su soporte ni su formato innovador lo que las caracterizó sino que nos interesa rescatar la relación de “contraposición" con la denominada "cultura oficial". Imposibilitadas de constituirse en alternativa de poder debido al contexto represivo, las revistas culturales "subterráneas" crecieron al margen de ese poder y cuestionaron su funcionamiento. Pero, ¿de qué manera lo cuestionaron? Consideramos que el cuestionamiento consistió, por un lado, en generar lazos de cooperación a través de la conformación de espacios de sociabilidad compuestos por grupos de jóvenes con diversas inquietudes. Por otro lado, si bien no se constituyeron en alternativa de poder, confrontaron con aquellas publicaciones denominadas "de superficie". A diferencia de ellas, las revistas "subterráneas" conformaron colectivos de publicaciones vinculadas con formaciones culturales, construyeron redes de solidaridad, cuestionaron el canon estético oficial, se vincularon con movimientos de Derechos Humanos y agrupaciones políticas. Esto, que en otro contexto hubiera sido una mera enunciación de características, en el contexto dictatorial cobraba otro sentido.

De la misma manera, deseo enfatizar las transformaciones que estas prácticas experimentaron con el triunfo del alfonsinismo. Estos cambios comienzan en los últimos años de la dictadura, cuando se empieza a producir paulatinamente cierta "apertura", lo que hizo que ciertas publicaciones comerciales se hicieran cargo de temas vedados al gran público hasta ese momento. La nueva coyuntura ubicó a las revistas en

Revista Eletrônica da ANPHLAC, n.10, p. 64-82, jan./jun. 2011.

http://revista.anphlac.org.br/index.php/revista 
otro plano: algunas se volcaron a publicaciones de mercado, otras desaparecieron y otras subsistieron por un tiempo pero con otra dinámica. El ascenso del radicalismo implicó un "balde de agua fría", en palabras de sus actores, quienes se encontraban mucho más cercanos a experiencias vinculadas con el peronismo o la izquierda.

Para finalizar, me interesa destacar el rol de las revistas culturales "subterráneas" en el rescate de su pasado y de su presente. Así como mantuvieron una relación de diálogo y a su vez de conflicto con ciertas tradiciones, configuraron durante la dictadura un vínculo particular con su presente, desafiando los límites impuestos por el poder militar e intentando "ir un poco más allá" de lo permitido y establecido.

\section{Bibliografía}

ALTAMIRANO, Carlos. El intelectual en la represión y en la democracia. Punto de Vista, n. 28, Buenos Aires, nov. 1986.

BREGA, Jorge. Poemas de Ausencia. Objetos y dibujos: Manuel Amigo. Buenos Aires: Ágora, 1984.

BOURDIEU, Pierre. Campo de poder y campo intelectual. Buenos Aires: Folios, 1983.

Las reglas del arte. Génesis y estructura del campo literario. Barcelona: Anagrama, 1995.

CALVEIRO, Pilar. Poder y desaparición. Buenos Aires: Colihue, 1998.

CANELO, Paula. El proceso en su laberinto. La interna militar de Videla a Bignone. Buenos Aires: Prometeo, 2008.

GUIARD, Silvia. Buenos Aires: el surrealismo en la lucha contra la dictadura. In: LÖWY, Michael. La estrella de la mañana: surrealismo y marxismo. Buenos Aires: El cielo por asalto, 2006.

MARCUS, Cecily. Las revistas culturales subterráneas en la dictadura. Ponencia para las II Jornadas de Historia de las Izquierdas. Buenos Aires, CeDInCI, diciembre de 2002.

MERO, Roberto. Revistas culturales. el aire contra la mordaza. Revista El Porteño, año 1, n. 3, marzo 1982.

PATIÑO, Roxana. Intelectuales en transición. Las revistas culturales argentinas (19811987). Cuadernos del Recienvenido, n. 4, Universidad de San Pablo, 1997. 
PEREDNIK, Santiago. Nueva poesía argentina durante la dictadura (1976-1983). Buenos Aires: Calle Abajo, 1989.

RIVERA, Jorge. El periodismo cultural. Buenos Aires: Paidós, 1995.

SOSNOWSKI, Saúl; PATIÑO, Roxana (Ed.). Una cultura para la democracia en América Latina. México: Fondo de Cultura Económica, 1999.

SIMPSON GRINBERG, Máximo (Compilador). Comunicación alternativa y cambio social. México: Premia Editorial, 1986.

WARLEY, Jorge. Revistas culturales de dos décadas (1970-1990). Cuadernos Hispanoamericanos, n. 517-519, jul.-sept. 1993.

WILLIAMS, Raymond. Cultura. Sociología de la Comunicación y del Arte. Barcelona: Paidós, 1981. Marxismo y literatura. Barcelona: Península, 1988.

Revista Eletrônica da ANPHLAC, n.10, p. 64-82, jan./jun. 2011.

http://revista.anphlac.org.br/index.php/revista 